\title{
MODELLING AND SIMULATION OF A MINING MACHINE EXCAVATING SEABED MASSIVE SULFIDE DEPOSITS
}

\author{
Dai, Y. ${ }^{* * *, \#}$; Chen, L. S. ; Zhu, X.* \& Liu, H.* \\ * College of Mechanical and Electrical Engineering, Central South University, Changsha 410083, China \\ ${ }^{* *}$ Shenzhen Research Institute, Central South University, Shenzhen 518000, China \\ E-Mail: daiyu_6@aliyun.com ( ${ }^{\#}$ Corresponding author)
}

\begin{abstract}
In this research, the mechanical characteristic parameters of the seabed massive sulfide (SMS) are obtained quantitatively using laboratory uniaxial compression strength (UCS) test and triaxial compression strength (TCS) test. A three-dimensional discrete element (DEM) model of the SMS is developed in the EDEM simulation environment and are then validated by numerically simulating the laboratory UCS and indirect tensile strength (Brazilian disc) tests. A new counter-rotating pick-type drum cutter for excavating the SMS is proposed, and a corresponding DEM model for the excavation process is established. Numerical simulations for the new counter-rotating cutter and a traditional single-rotating cutter are conducted, and the cutter forces in three orthogonal directions and the torques are obtained and compared. By integrating the new counter-rotating cutter, a three-dimensional multi-rigid-body dynamic model of a SMS mining machine is developed in the RecurDyn simulation environment, and simulations are conducted to evaluate its trafficability and mobility performance under the effect of the excavating cutter on the seabed complex terrain. This research can provide valuable and effective modelling methods for seabed mineral excavation process simulation, mining tool optimization and design and mining machine performance evaluation.

(Received, processed and accepted by the Chinese Representative Office.)
\end{abstract}

Key Words: Seabed Massive Sulfide, Seabed Mining Machine, Laboratory Mechanical Tests, Excavation Cutter, Discrete Element Model, Numerical Simulation

\section{INTRODUCTION}

As the gradual reduction of land-based mineral resources and the strong demand for metallic materials, the extremely rich mineral resources on the deep seabed have aroused great interest from the global mining industry. Seabed massive sulfide (SMS) deposits, which are rich in both, base and precious metals, are likely to be commercially exploited in the near future [1]. The seabed mining machine and the excavation cutter are crucial pieces of equipment to ensure continuous excavation operation efficiency and the safety of a seabed mining system.

To evaluate the locomotion and mobility performance of a seabed mining machine, Hong et al. adopted a new technique based on Euler parameters for analysing the dynamic characteristics of a mining machine moving on seabed [2]. Li and Zhong built a virtual prototype of an ocean mining machine and performed simulations to examine the machine's mobility and manoeuvrability [3]. Dai and Liu built a seabed tracked mining machine to be a single-rigid-body model integrating a track-soil discretized interaction mechanical model [4]. Dai et al. established a novel multi-rigid-body model of a seabed mining machine that integrated a terramechanical model of seabed particular soil; their simulations demonstrated the machine has favourable mobility performance on the seabed [5].

To predict and understand the underwater excavation mechanism of a tool-rock system, Miedema performed a series of studies, including the development of a mathematical model to estimate the cutting forces for underwater hyperbaric conditions and comparison with atmospheric rock cutting [6-8], and performed a cutting experiment in a pressure tank [9]. Chen et al. established a numerical model of the dredging excavation by using both the discrete element method (DEM) to model the solid particles and the finite volume method to 
compute the fluid pressure [10]. In addition, studies have been carried out for the rock breaking simulation in atmospheric circumstances. Rojek et al. used the DEM to simulate the rock breaking with road-header picks for underground excavation and compared numerical results with test data [11]. Su and Akcin used a particle flow simulation code PFC3D to model the rock cutting; compared the theoretical, numerical and experimental models [12]. Van Wyk et al. performed a numerical simulation of the tool forces from rock breaking by a DEM and simulated different rock cutting tools to record the tool forces [13]. Duan and Kwok conducted Brazilian disc tests to study the mechanical behaviours of anisotropic rocks based on DEM simulations and found good conformity between the simulation results and the test results [14]. Estay and Chiang used a new method known as the discrete crack model (DCM) to model rock broken and comparatively analysed three loading cases to validate this methodology [15]. Yuan et al. adopted the discrete element program PFC2D to inspect whether the tailing dam is stable and made comparison with the limit equilibrium method [16]. Menezes et al. adopted a finite element software LS-DYNA for simulating the rock broken under mechanical cutting [17]. Li et al. also used the LS-DYNA to simulate the different cutter's rock breaking and obtained forces in different directions [18]. Huang et al. simulated the cutting process by the LS-DYNA3D program, and their simulation results were validated through comparison with the theoretical model results, DEM model results and experimental data [19].

However, some key issues remain to be further studied. The particular mechanical parameters of the SMS deposit have not yet been ascertained accurately and comprehensively; thus, an excavation mechanism model for the SMS, either a numerical simulation model or a mathematical model, has yet to be established. Furthermore, a dynamic behaviour analysis for a SMS mining machine that integrates an excavating cutter has not been realized. Considering these deficiencies, the studies here described were carried out.

\section{MECHANICAL PARAMETER DETERMINATION TESTS}

To accurately and comprehensively ascertain the particular mechanical parameters of the SMS deposit, UCS and TCS tests were carried out on SMS samples obtained from ocean in situ sampling. Fig. 1 shows the UCS and TCS tests using a MTS 815 high-precision rock mechanics testing machine, which consists of a loading device, a triaxial cell, a confining pressure intensifier, a pore pressure intensifier, controllers, a hydraulic power supply and a computer system.

A series of tests was performed on the different SMS samples, and through data analysis and processing, the following critical parameters of the SMS were obtained.

Table I: Critical physical and mechanical characteristic parameters of the SMS.

\begin{tabular}{|l|c|}
\hline Wet density $\left(\mathrm{g} / \mathrm{cm}^{3}\right)$ & 2.94 \\
\hline Dry density $\left(\mathrm{g} / \mathrm{cm}^{3}\right)$ & 2.60 \\
\hline UCS $(\mathrm{MPa})$ & 10.243 \\
\hline Elasticity modulus $(\mathrm{MPa})$ & 11487 \\
\hline Poisson's ratio & 0.11 \\
\hline Cohesion $(\mathrm{MPa})$ & 2.447 \\
\hline Internal friction angle (Degrees) & 38.04 \\
\hline
\end{tabular}




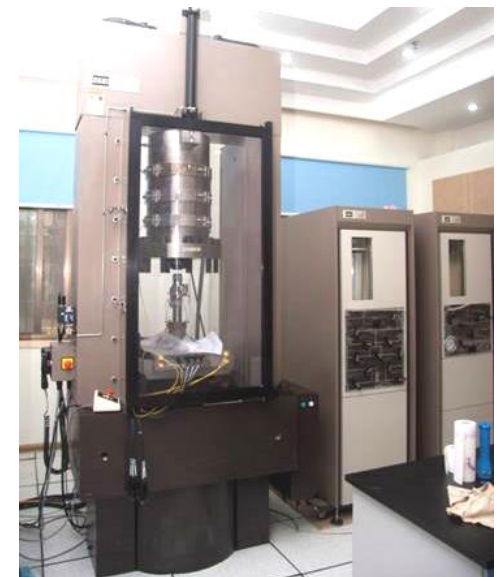

a)

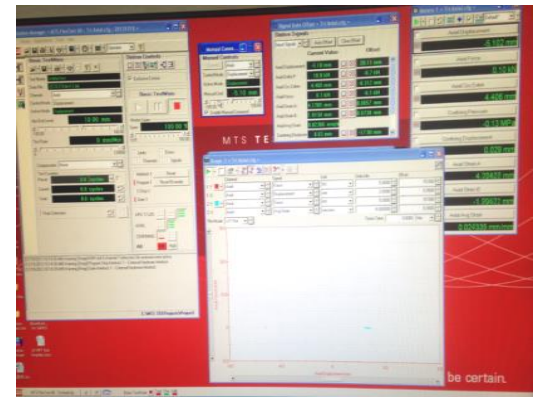

d)

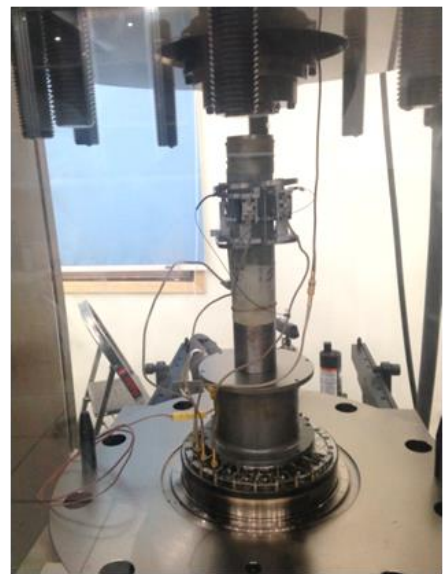

b)

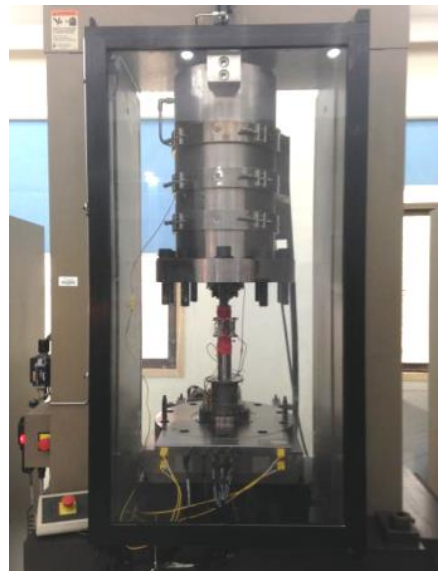

c)

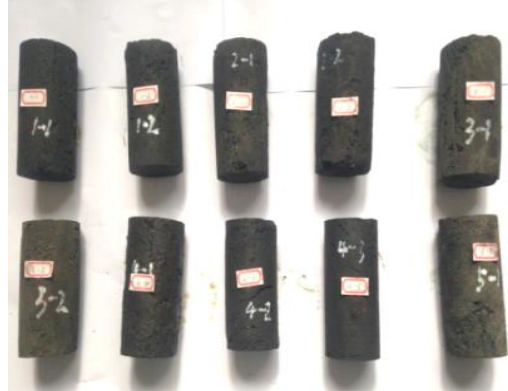

e)

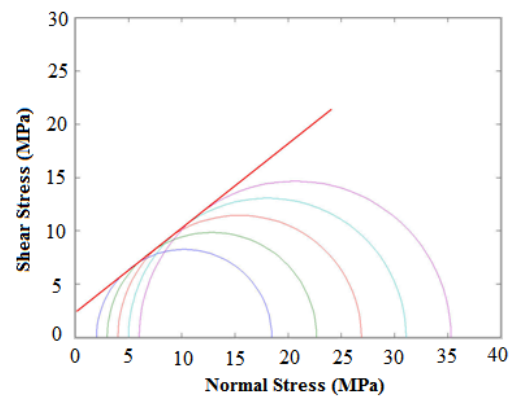

f)

Figure 1: Laboratory mechanical tests photos on the SMS samples: a) total testing system; b) UCS test; c) TCS test; d) data acquisition and processing interface; e) prepared test pieces of SMS samples; f) Mohr's stress circle obtained from TCS test.

\section{DISCRETE ELEMENT MODELING OF SMS}

The particle flow simulation program EDEM was used to establish a 3D discrete element model of the SMS. The Hertz-Mindlin contact model, which is shown in Fig. 2 and available in EDEM, is used to bond the discrete particles of the SMS; it consists of a normal force, a tangential force and a sliding force. The micromechanical parameters should be determined accurately such that the macromechanical parameters of the DEM model will conform to the laboratory test data.

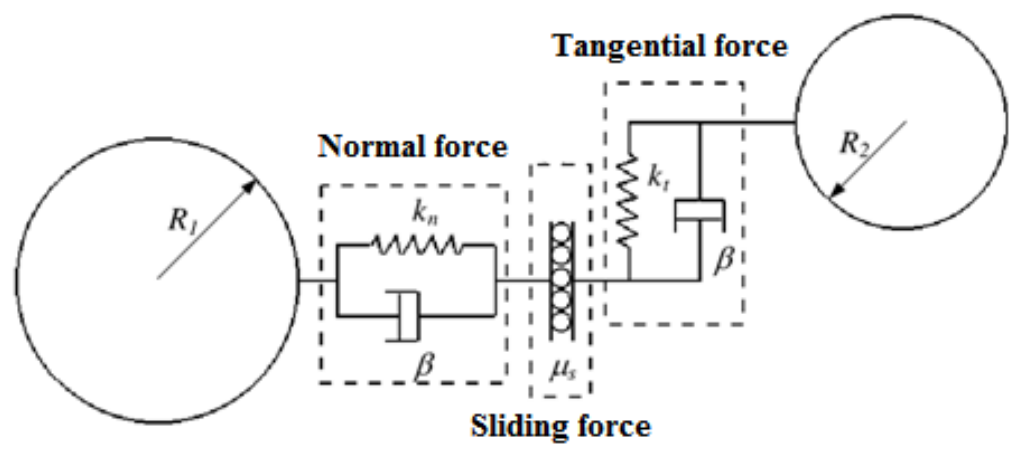

Figure 2: Schematic diagram of the Hertz-Mindlin contact model for the DEM.

There are five micromechanical parameters in the Hertz-Mindlin model that need to be calibrated for DEM modelling, including the bond radius, the normal ultimate strength, the tangential ultimate strength, the normal stiffness and the tangential stiffness per bond unit area, which can be computed as 


$$
\left\{\begin{array}{l}
R=\frac{R_{1}+R_{2}}{2} \\
k_{n}=\frac{A E_{c}}{L} \\
k_{t}=\frac{12 I E_{c}}{L^{3}} \\
\frac{\sigma_{c}}{\tau_{b, m}}=2.11+0.38 \ln \mu-0.63 \ln \frac{\tau_{b, m}}{\sigma_{b, m}}-0.22 \frac{\tau_{b, m}}{\sigma_{b, m}} \ln \mu \\
\frac{E}{E_{c}}=0.78+0.14 \ln \frac{L}{R}-0.34 \ln \frac{k_{n}}{k_{s}}
\end{array}\right.
$$

where $R$ is the particle equivalent radius; $k_{n}$ and $k_{t}$ are the normal stiffness and tangential stiffness per bond unit area, respectively; $A$ is the bond sectional area; $I$ is the rotational inertia; $E$ is Young's modulus of the particle; $E_{c}$ is the elasticity modulus; $\sigma_{c}$ is the normal ultimate stress; $\tau_{b, m}$ is the tangential ultimate stress; $\mu$ is the factor of friction between particles; $L$ is the centre distance between particles.

Eq. (1) is used to first estimate the data ranges for the five micromechanical parameters, then to simulate the UCS test and indirect tensile (Brazilian disc) test in EDEM, and finally to compare the macromechanical parameters measured in the DEM simulation with those in laboratory tests to validate the computational accuracy of the DEM model. The following micromechanical parameters were preliminarily determined through repeated verifications.

Table II: Determined micromechanical parameters for the DEM model of SMS.

\begin{tabular}{|l|c|c|}
\hline Normal ultimate stress $(\mathrm{Pa})$ & $\sigma_{c}$ & $4.9 \times 10^{9}$ \\
\hline Tangential ultimate stress $(\mathrm{Pa})$ & $\tau_{b, m}$ & $4.7 \times 10^{9}$ \\
\hline Normal stiffness per bond unit area $\left(\mathrm{N} / \mathrm{m}^{2}\right)$ & $k_{n}$ & $1.1 \times 10^{8}$ \\
\hline Tangential stiffness per bond unit area $\left(\mathrm{N} / \mathrm{m}^{2}\right)$ & $k_{t}$ & $1.0 \times 10^{8}$ \\
\hline
\end{tabular}

\subsection{DEM simulation of laboratory UCS test}

Based on the principle of the UCS test, a corresponding discrete element simulation model as shown in Fig. 3 is built in the EDEM environment. The numbers 1 and 3 in Fig. 3 a denote the upper and lower pressure plates, respectively. Upon applying a specific downward movement velocity for the upper pressure plate, Fig. $3 \mathrm{~b}$ shows that the fracture occurs during the simulation, and Fig. $3 \mathrm{c}$ records the force change acting on the upper plate.

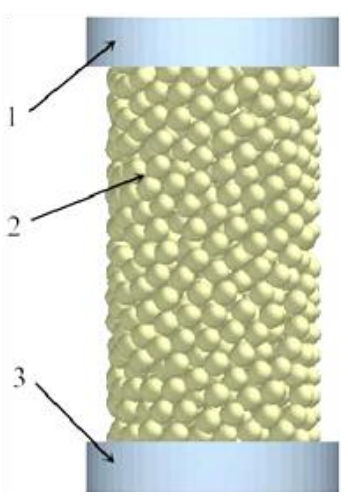

a)

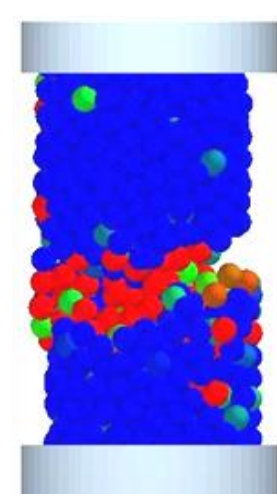

b)

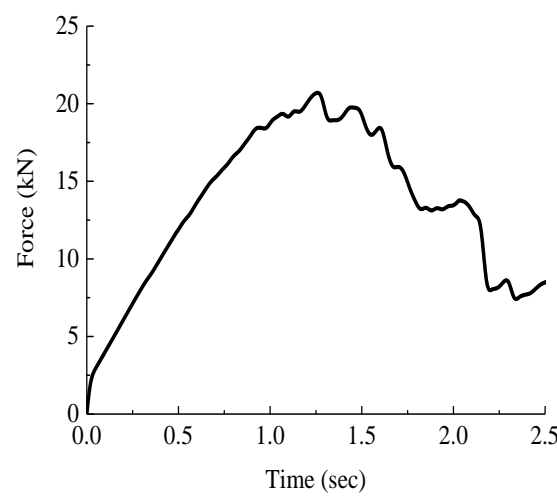

c)

Figure 3: DEM simulation of laboratory UCS test: a) DEM model of a simulated test piece; b) fracture simulation; c) force change acting on the upper pressure plate. 
The simulated uniaxial compression strength can be computed from the DEM simulation of the SMS to be approximately $\sigma_{R}=10.561 \mathrm{MPa}$.

\subsection{DEM simulation of Brazilian disc test}

Similarly, Fig. 4 illustrates the DEM simulation process of the simulated Brazilian disc test.

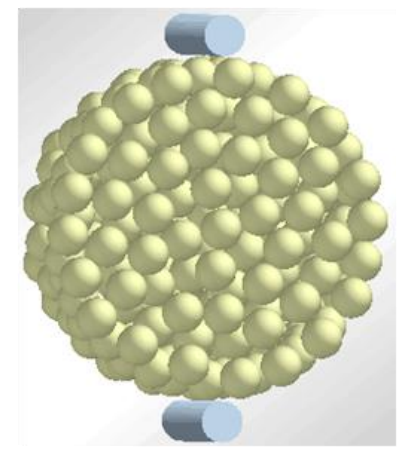

a)

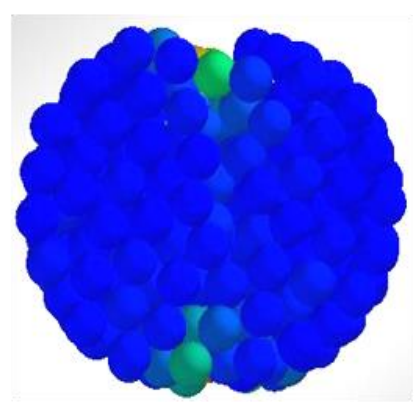

b)

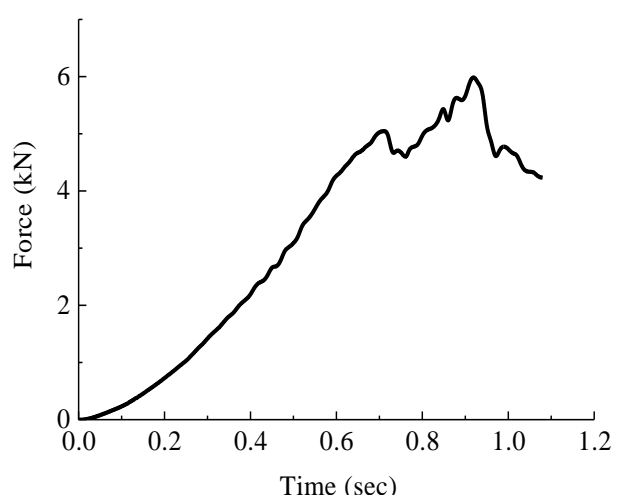

c)

Figure 4: DEM simulation of indirect tensile (Brazilian disc) test: a) DEM model of a simulated test piece; b) fracture simulation; c) force change acting on the upper pressure bar.

Accordingly, the simulated tensile strength from the DEM simulation of the SMS can be computed to be approximately $\sigma_{t}=2.558 \mathrm{MPa}$. According to the Hook-Brown empirical formula, which follows, with the overall consideration of the above simulation results, the cohesion $C=2.599 \mathrm{MPa}$ and the internal friction angle $\varphi=37.59^{\circ}$ of the SMS can be obtained.

$$
\left\{\begin{array}{l}
C=\frac{1}{2} \sqrt{\sigma_{R} \sigma_{t}} \\
\varphi=\arcsin \frac{\sigma_{R}-\sigma_{t}}{\sigma_{R}+\sigma_{t}}
\end{array}\right.
$$

Table III summarizes and compares the measured mechanical parameters from the laboratory tests and corresponding DEM numerical simulations of the SMS.

Table III: Mechanical parameter comparisons.

\begin{tabular}{|l|c|c|c|}
\hline & UCS (MPa) & Internal friction angle (Degree) & Cohesion (MPa) \\
\hline DEM simulations & 10.561 & $37.59^{\circ}$ & 2.599 \\
\hline Laboratory tests & 10.243 & $38.04^{\circ}$ & 2.447 \\
\hline Errors & $3.1 \%$ & $1.2 \%$ & $6.2 \%$ \\
\hline
\end{tabular}

These results prove that the computational accuracy of the DEM numerical simulation is sufficient and can be applied to efficiently numerically simulate the SMS excavation process using the mining machine's cutter.

\section{NUMERICAL SIMULATIONS OF CUTTER EXCAVATING SMS}

A new counter-rotating pick-type drum cutter for excavating the SMS is proposed and designed as illustrated in Fig. 5 to achieve better excavation and collection efficiency because it can spread the excavation load between two cutters. It can also funnel the cuttings towards a 
central collection location between the cutters to prevent these broken particles from being lost as plumes.

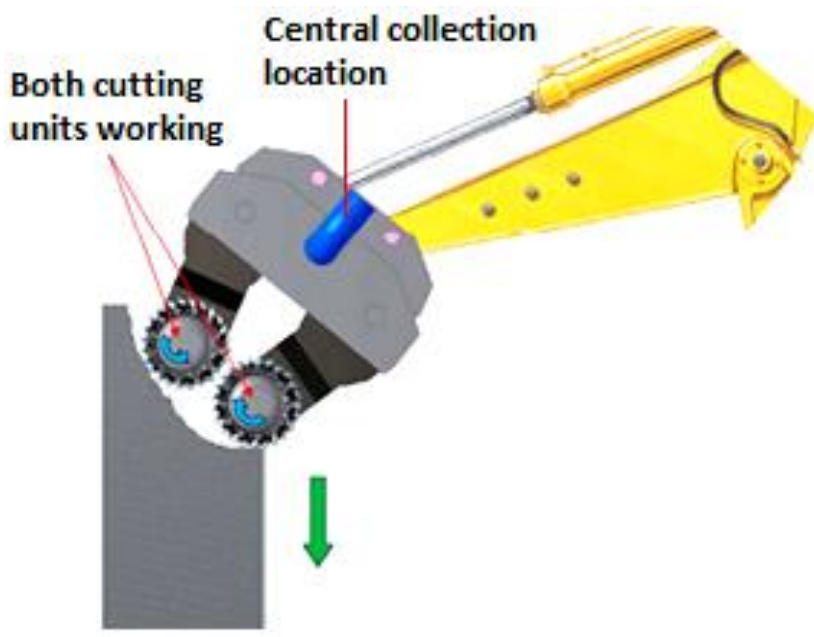

a)

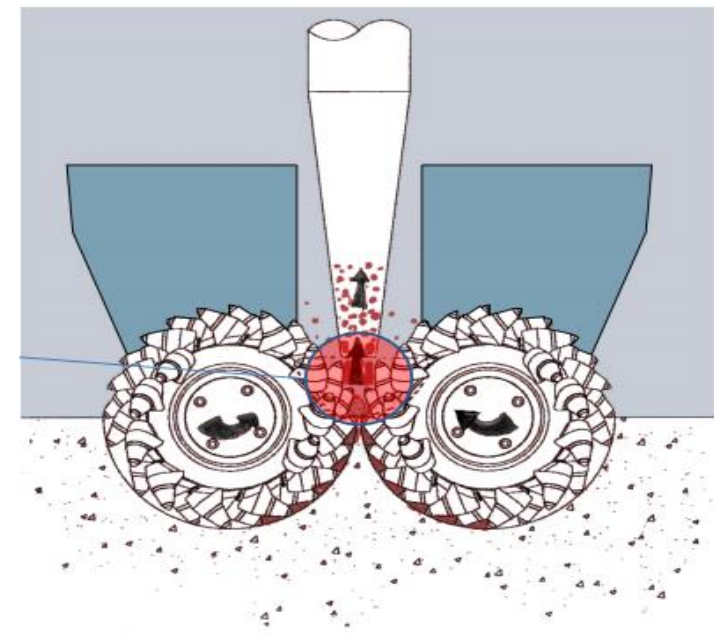

b)

Figure 5: Schematic illustration of a new counter-rotating drum cutter: a) structure illustration; b) expected collection effect.

The corresponding 3D DEM model for the new counter-rotating cutter excavating the SMS is established in Fig. 6, and the excavation effect is compared with that of a traditional single rotating cutter.

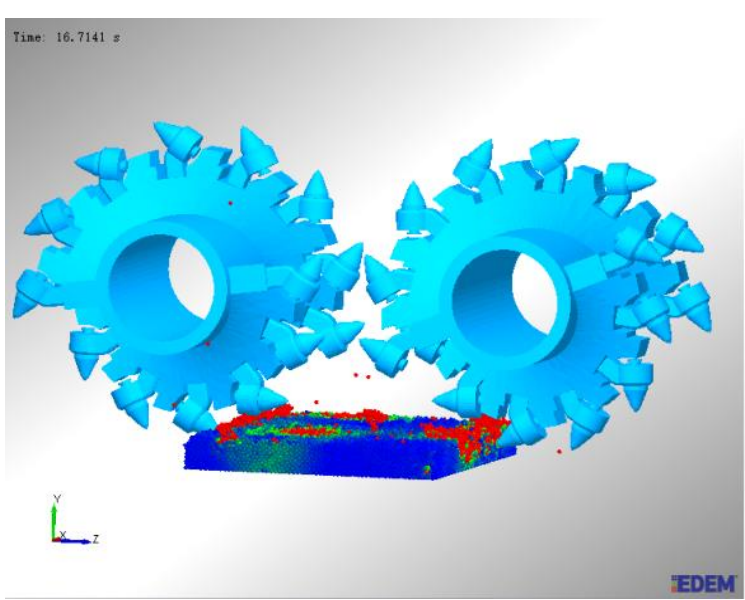

a)

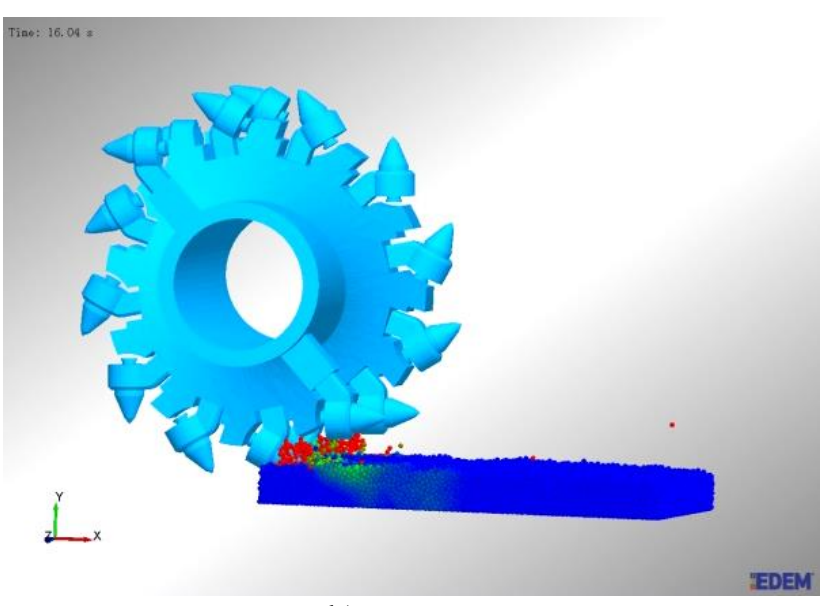

b)

Figure 6: 3D discrete element simulation model of cutters excavating SMS: a) New counter-rotating pick-type drum cutter; b) traditional single rotating pick-type drum cutter.

Fig. 7 compares the cutter forces in three orthogonal directions, including the excavation forces, normal forces and side forces obtained from numerical simulations. 


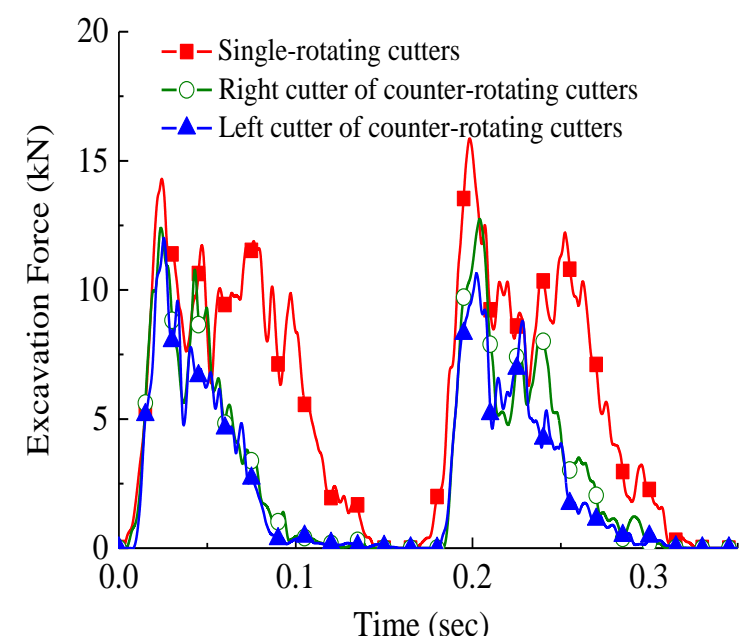

a)

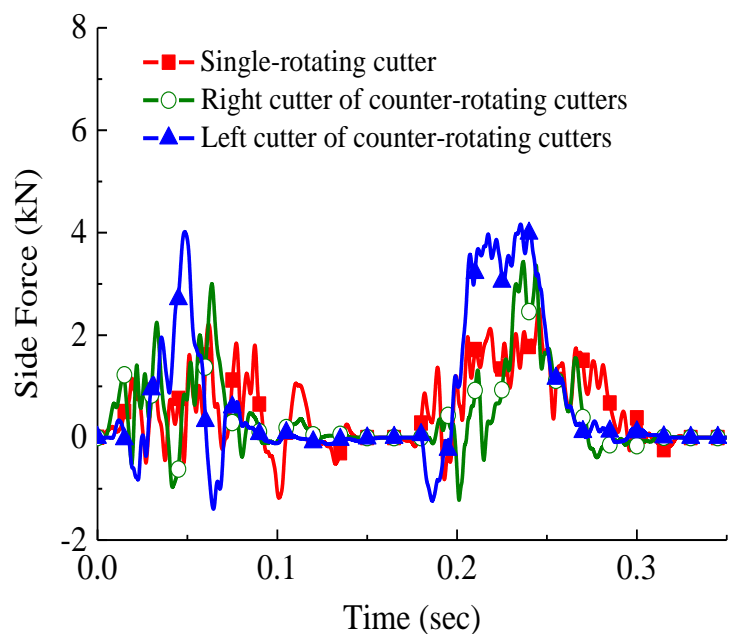

c)

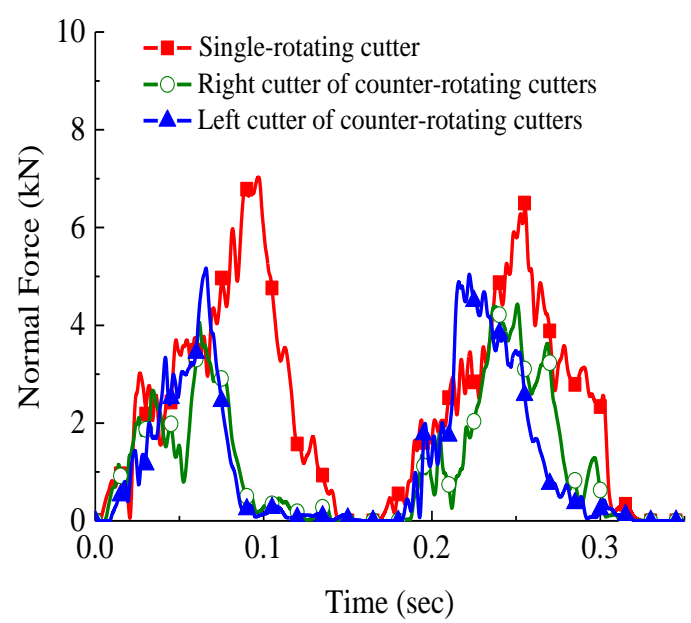

b)

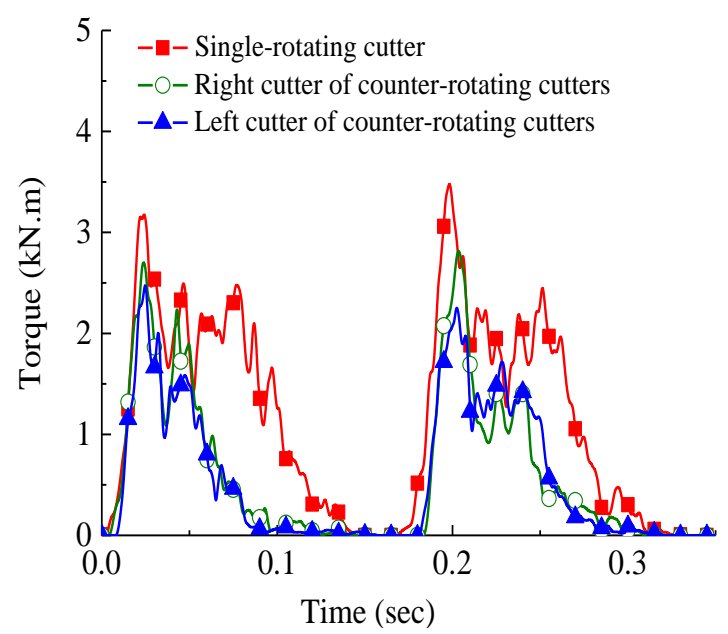

d)

Figure 7: Cutter forces and torque simulations: a) excavation forces; b) normal forces; c) side forces; d) torques.

Table IV summarizes the DEM numerical simulation results.

Table IV: DEM numerical simulation results.

\begin{tabular}{|c|c|c|c|c|}
\hline \multirow{2}{*}{\multicolumn{2}{|c|}{ Parameters }} & \multicolumn{3}{|c|}{ Values } \\
\hline & & $\begin{array}{l}\text { Single rotating } \\
\text { cutter }\end{array}$ & $\begin{array}{l}\text { Right cutter of } \\
\text { counter-rotating } \\
\text { cutters }\end{array}$ & $\begin{array}{c}\text { Left cutter of } \\
\text { counter-rotating } \\
\text { cutters }\end{array}$ \\
\hline \multirow{3}{*}{$\begin{array}{c}\text { Excavation } \\
\text { forces } \\
(\mathrm{kN})\end{array}$} & Maximum value & 16.3 & 12.82 & 12.69 \\
\hline & Mean value & 6.58 & 3.82 & 3.20 \\
\hline & Fluctuation coefficient & 0.66 & 1.03 & 1.03 \\
\hline \multirow{3}{*}{$\begin{array}{c}\text { Normal } \\
\text { forces } \\
(\mathrm{kN})\end{array}$} & Maximum value & 7.37 & 4.57 & 5.57 \\
\hline & Mean value & 2.74 & 1.44 & 1.48 \\
\hline & Fluctuation coefficient & 0.69 & 0.90 & 1.06 \\
\hline \multirow{3}{*}{$\begin{array}{l}\text { Side forces } \\
\qquad(\mathrm{kN})\end{array}$} & Maximum value & 2.75 & 3.56 & 4.50 \\
\hline & Mean value & 0.78 & 0.70 & 1.03 \\
\hline & Fluctuation coefficient & 0.88 & 1.17 & 1.28 \\
\hline \multirow{2}{*}{$\begin{array}{l}\text { Torque } \\
(\mathrm{kNm})\end{array}$} & Maximum value & 3.47 & 2.91 & 2.52 \\
\hline & Mean value & 1.32 & 0.75 & 0.68 \\
\hline
\end{tabular}


The excavation forces, normal forces and torques acting on the left cutter and right cutter of the new counter-rotating cutters are all significantly less than those acting on the single rotating cutter, which demonstrates that an interaction effect occurs between the counter-rotating cutters that cause a counteraction that can spread the excavation load. Simultaneously, it can, in a way, throw the cuttings towards the central collection location between the left and right cutters.

\section{DYNAMIC SIMULATIONS OF A SMS MINING MACHINE}

The dynamic simulation program RecurDyn is adopted to build a multi-rigid-body model of a SMS mining machine that has a special design with four tracks to effectively improve its tractive performance and obstacle-surmounting ability, as illustrated in Fig. 8. The particular seabed terramechanical model, which has been developed in previous research [5], is integrated into the multi-rigid-body model of the SMS mining machine. The newly designed counter-rotating cutter head and its excavation loads obtained from the above DEM numerical simulation are all applied on the model of the SMS mining machine.

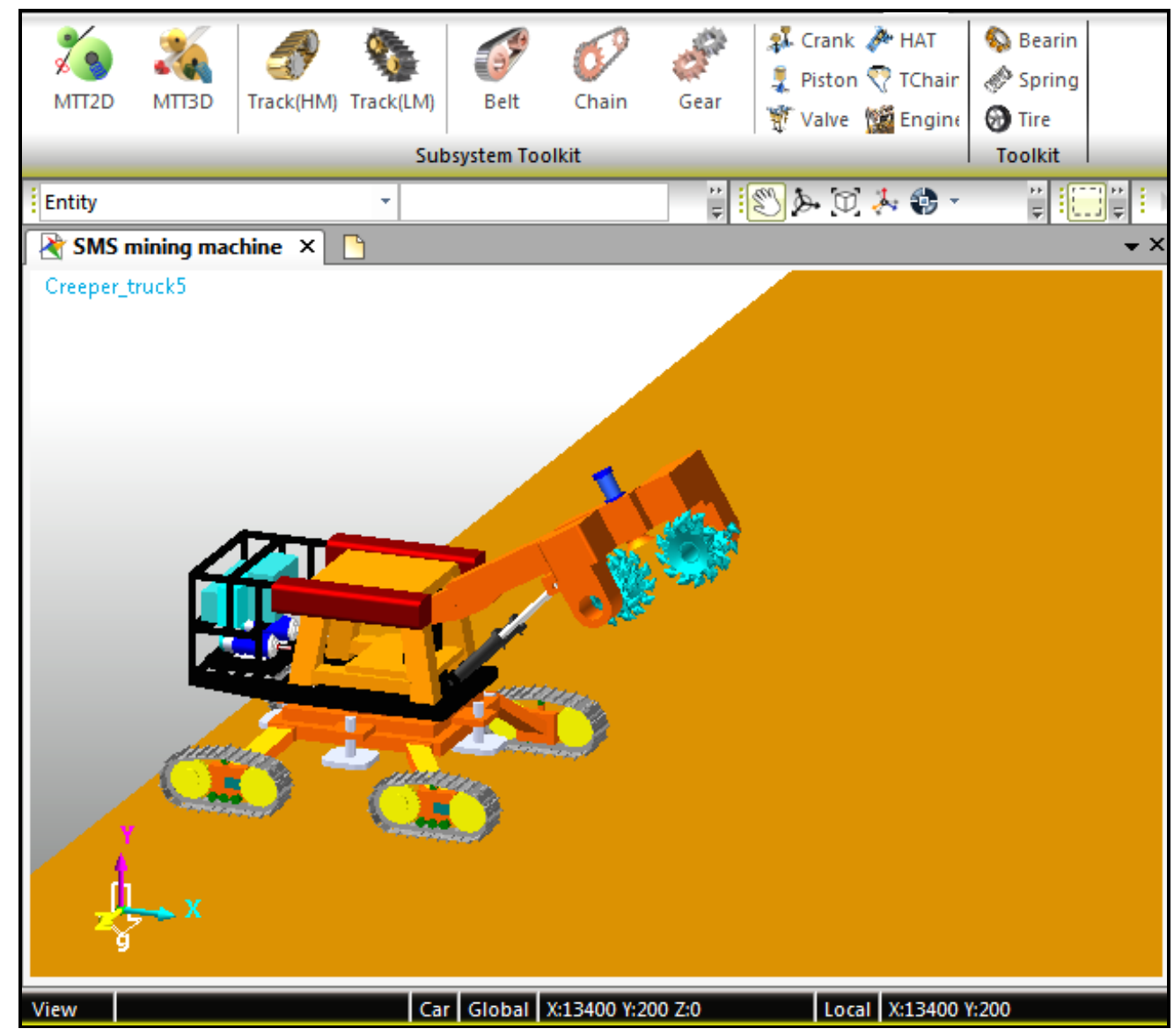

Figure 8: A multi-rigid-body simulation model of a SMS mining machine.

Fig. 9 shows the rectilinear movement simulation of the SMS mining machine at a theoretical input speed of $0.5 \mathrm{~m} / \mathrm{s}$. Its average sinkage is approximately $80 \mathrm{~mm}$, which can satisfy the design requirement and accord with the actual movement condition.

The reasonable velocity ratio for two tracks of a mining machine during turning on the seabed extremely soft sediment should not exceed 1.4 to guarantee its safe turning and avoid large sinkages. Hence, the turning velocity ratio is set to 1.4 , meanwhile the input speed for the low speed track is set to $0.5 \mathrm{~m} / \mathrm{s}$. Fig. 10 illustrates the movement simulation curves. 


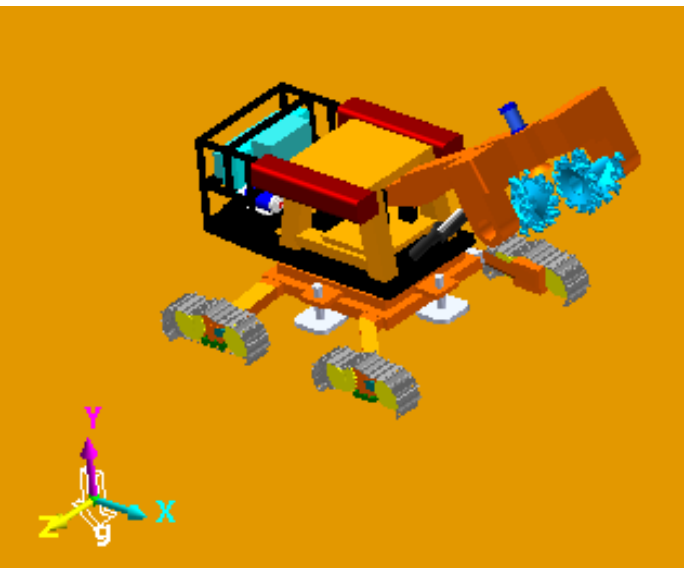

a)

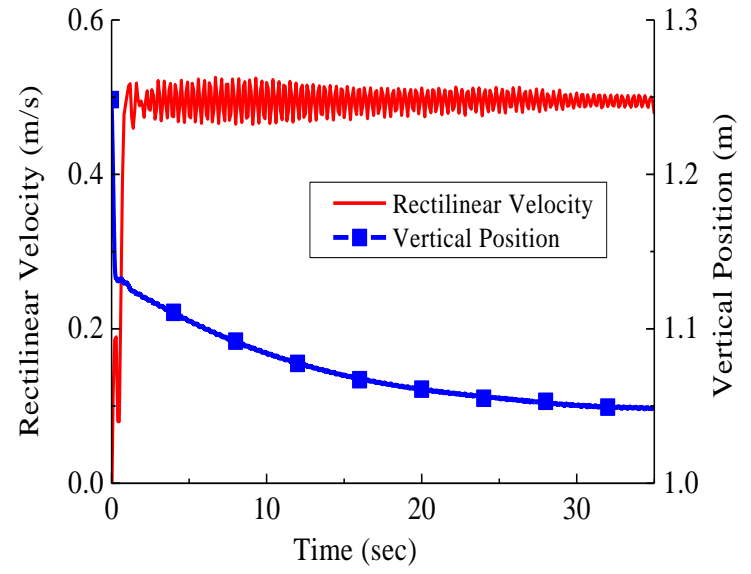

b)

Figure 9: Rectilinear movement simulation: a) simulation model interface; b) velocity and vertical position curves.

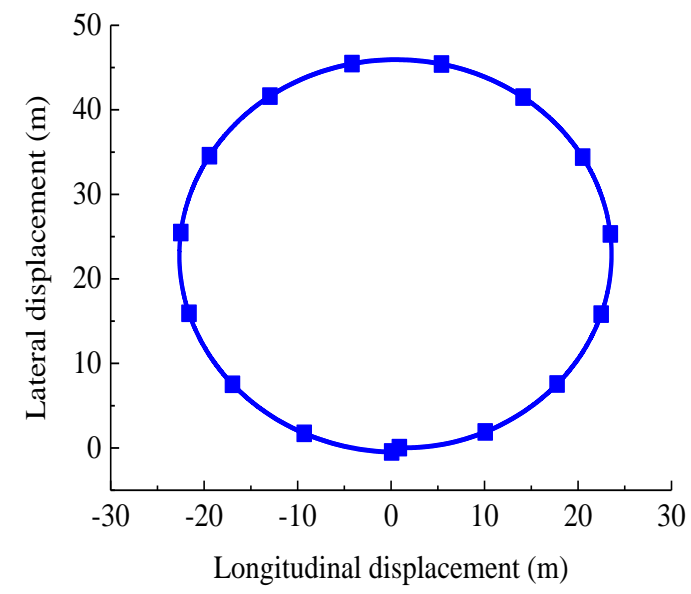

a)

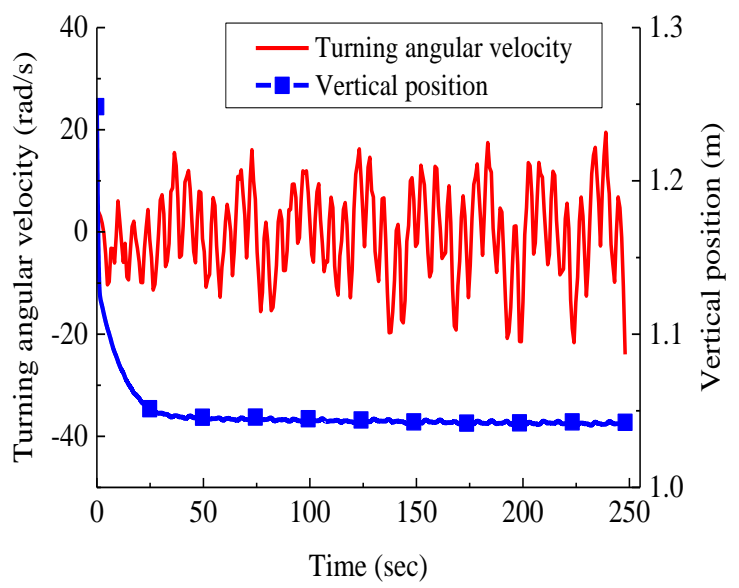

b)

Figure 10: Turning simulation: a) trajectory curve; b) turning angular velocity and vertical position curves.

The topography characteristics of the SMS deposit are especially complex, and according to the obstacle-surmounting design requests for a SMS mining machine, an obstaclesurmounting simulation is performed.

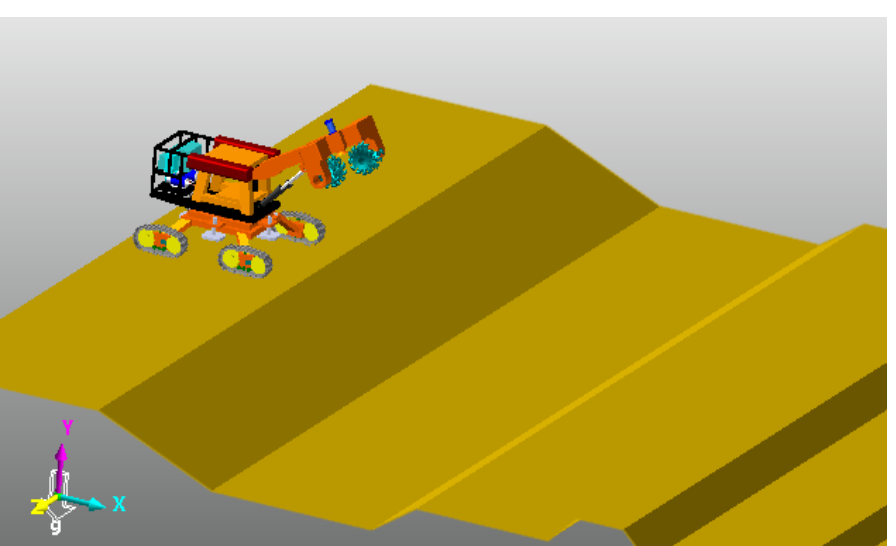

a)

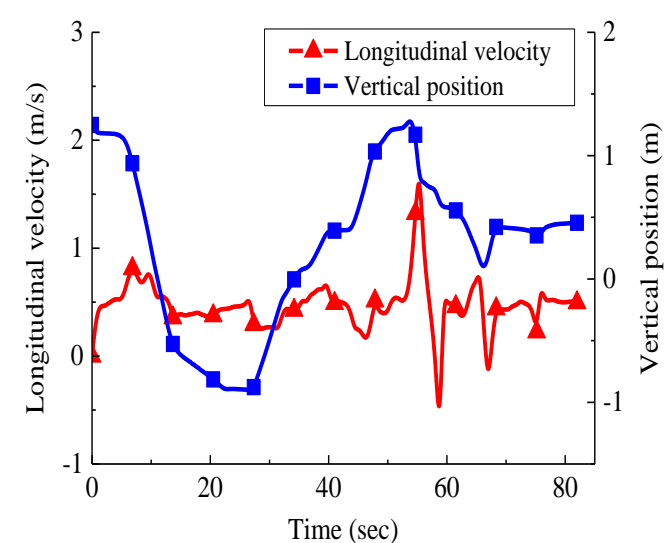

b)

Figure 11: Obstacle-surmounting simulation: a) simulation model interface; b) velocity and vertical position curves. 
The dynamic simulation can well reflect the practical movements of the SMS mining machine. It can be concluded that the grade ability and trench crossing ability of the mining machine on the SMS deposit can well meet the operational demands and the SMS mining machine has favourable locomotion performance on the complex seabed terrain.

\section{CONCLUSIONS}

The main conclusions can be summarized as follows from this research.

(1) The particular mechanical characteristic parameters of the seabed massive sulfide, including the UCS, elasticity modulus, Poisson's ratio, internal friction angle and cohesion, have been quantitatively determined through laboratory UCS and TCS tests on SMS samples.

(2) A 3D discrete element simulation model of the SMS has been established in the EDEM environment. The computational accuracy of the DEM model for the SMS has been validated by numerically simulating the UCS test and Brazilian disc test in the EDEM because the numerical simulations results agree very well with the laboratory test results.

(3) A new counter-rotating pick-type drum cutter for excavating the SMS has been proposed and designed. 3D numerical simulations compared to a single rotating cutter have demonstrated the reasonability and superiority of the new counter-rotating cutter due to the interaction effect that occurs between the counter-rotating cutters, which significantly spreads the excavation load. Simultaneously, it can, in a way, throw the cuttings towards the central collection location between the cutters.

(4) A multi-rigid-body dynamic model of a SMS mining machine has been developed in the RecurDyn environment that integrates a newly designed counter-rotating cutter. Simulations prove the SMS mining machine has favourable mobility and locomotion performance under the excavation effect of the cutter on the complex seabed terrain.

\section{ACKNOWLEDGEMENTS}

The authors acknowledge the financial support from the National High Technology Research and Development Program (Grand No. 2012AA091201), and the National Natural Science Foundation of China (Grand No. 51074179 and No. 51105386).

\section{REFERENCES}

[1] Hoagland, P.; Beaulieu, S.; Tivey, M. A.; Eggert, R. G.; German, C.; Glowka, L.; Lin, J. (2010). Deep-sea mining of seafloor massive sulfides, Marine Policy, Vol. 34 , No. 3, 728-732, doi:10.1016/j.marpol.2009.12.001

[2] Kim, H.-W.; Hong, S.; Choi, J. S.; Yeu, T.-K. (2005). Dynamic analysis of underwater tracked vehicle on extremely soft soil by using Euler parameters, Proceedings of the $6^{\text {th }}$ ISOPE Ocean Mining Symposium, 141-148

[3] Li, L.; Zhong, J. (2005). Research of China's pilot-miner in the mining system of poly-metallic nodule, Proceedings of the $6^{\text {th }}$ ISOPE Ocean Mining Symposium, 124-131

[4] Dai, Y.; Liu, S.-J. (2013). Theoretical design and dynamic simulation of new mining paths of tracked miner on deep seafloor, Journal of Central South University, Vol. 20, No. 4, 918-923, doi: $10.1007 / \mathrm{s} 11771-013-1566-\mathrm{Z}$

[5] Dai, Y.; Zhu, X.; Chen, L. S.; Liu, H.; Zhang, T.; Liu, S. J. (2015). A new multi-body dynamic model for seafloor miner and its trafficability evaluation, International Journal of Simulation Modelling, Vol. 14, No. 4, 732-743, doi:10.2507/IJSIMM14(4)CO19

[6] Miedema, S. A. (2010). New developments of cutting theories with respect to offshore applications, Proceedings of the $20^{\text {th }}$ International Offshore and Polar Engineering Conference, 694-701 
[7] Miedema, S. A. (2010). The influence of the strain rate on cutting processes, Proceedings of the $20^{\text {th }}$ International Offshore and Polar Engineering Conference, 702-708

[8] Miedema, S. A.; Zijsling, D. (2012). Hyperbaric rock cutting, Proceedings of the ASME $31^{\text {st }}$ International Conference on Ocean, Offshore and Arctic Engineering, 103-116

[9] Grima, M. A.; Miedema, S. A.; van de Ketterij, R. G.; Yenigul, N. B.; van Rhee, C. (2015). Effect of high hyperbaric pressure on rock cutting process, Engineering Geology, Vol. 196, 24-36, doi:10.1016/j.enggeo.2015.06.016

[10] Chen, X.; Miedema, S. A.; van Rhee, C. (2015). Numerical modeling of excavation process in dredging engineering, Procedia Engineering, Vol. 102, 804-814, doi:10.1016/j.proeng. 2015.01.194

[11] Rojek, J.; Onate, E.; Labra, C.; Kargl, H. (2011). Discrete element simulation of rock cutting, International Journal of Rock Mechanics and Mining Sciences, Vol. 48, No. 6, 996-1010, doi:10.1016/j.ijrmms.2011.06.003

[12] Su, O.; Akcin, N. A. (2011). Numerical simulation of rock cutting using the discrete element method, International Journal of Rock Mechanics and Mining Sciences, Vol. 48, No. 3, 434-442, doi:10.1016/j.ijrmms.2010.08.012

[13] van Wyk, G.; Els, D. N. J.; Akdogan, G.; Bradshaw, S. M.; Sacks, N. (2014). Discrete element simulation of tribological interactions in rock cutting, International Journal of Rock Mechanics and Mining Sciences, Vol. 65, 8-19, doi:10.1016/j.ijrmms.2013.10.003

[14] Duan, K.; Kwok, C. Y. (2015). Discrete element modeling of anisotropic rock under Brazilian test conditions, International Journal of Rock Mechanics and Mining Sciences, Vol. 78, 46-56, doi:10.1016/j.ijrmms.2015.04.023

[15] Estay, D. A.; Chiang, L. E. (2013). Discrete crack model for simulating rock comminution processes with the Discrete Element Method, International Journal of Rock Mechanics and Mining Sciences, Vol. 60, 125-133, doi:10.1016/j.ijrmms.2012.12.041

[16] Yuan, L.-W.; Li, S.-M.; Peng, B.; Chen, Y.-M. (2015). Study on failure process of tailing dams based on particle flow theories, International Journal of Simulation Modelling, Vol. 14, No. 4, 658-668, doi: 10.2507/IJSIMM14(4)8.322

[17] Menezes, P. L.; Lovell, M. R.; Avdeev, I. V.; Higgs III, C. F. (2014). Studies on the formation of discontinuous rock fragments during cutting operation, International Journal of Rock Mechanics and Mining Sciences, Vol. 71, 131-142, doi:10.1016/j.ijrmms.2014.03.019

[18] Li, X. Y.; Lv, Y. G.; Jiang, S. B.; Zeng, Q. L. (2016). Effects of spiral line for pick arrangement on boom type roadheader cutting load, International Journal of Simulation Modelling, Vol. 15, No. 1, 170-180, doi:10.2507/IJSIMM15(1)CO4

[19] Huang, J.; Zhang, Y.-M.; Zhu, L.-S.; Wang, T. (2016). Numerical simulation of rock cutting in deep mining conditions, International Journal of Rock Mechanics and Mining Sciences, Vol. 84, 80-86, doi:10.1016/j.j.jrmms.2016.02.003 